\title{
Gender-related risk factors for perioperative stroke after carotid endarterectomy in symptomatic patients
}

\author{
Mirosław Stelągowski ', A, C, E, F, Anna Kasielska-Trojann, B-F, Katarzyna Bogusiak 3, B-F, Dariusz Timler 4, C, E, F, \\ Marek Łysakowski ${ }^{1}, B, C, F$, Piotr Kaźmierski ${ }^{1}, B, C, F$, Michał Pająk ${ }^{1}, B, C, F$, Małgorzata Szostek ${ }^{5, E, F}$ \\ ${ }^{1}$ Department of Vascular, General and Oncologic Surgery, Copernicus Memorial Hospital, Łódź, Poland \\ 2 Plastic, Reconstructive and Esthetic Surgery Clinic, University Hospital No. 1, Łódź, Poland \\ ${ }^{3}$ Department of Maxillofacial Suregry, Medical University of Lodz, Poland \\ ${ }^{4}$ Department of Emergency Medicine, Medical University of Lodz, Poland \\ ${ }^{5}$ Department of General Surgery and Thoracic Diseases, Medical Academy of Warsaw, Poland \\ A - research concept and design; $B$ - collection and/or assembly of data; $C$ - data analysis and interpretation; \\ $D$ - writing the article; $E$ - critical revision of the article; $F$ - final approval of the article
}

Address for correspondence

Anna Kasielska-Trojan

E-mail: annakas@toya.net.pl

Funding sources

None declared

\section{Conflict of interest}

None declared

Received on January 31,2016

Reviewed on May 29, 2016

Accepted on January 4, 2017

\begin{abstract}
Background. Carotid endarterectomy (CEA) is a surgical procedure used in ischemic brain stroke prevention in patients with symptomatic and asymptomatic severe carotid artery stenosis.

Objectives. This study compares perioperative stroke or death rate after carotid endarterectomy (CEA) in male and female patients, and determines risk factors for perioperative incidents in women and men.

Material and methods. The outcome of surgical treatment of 269 consecutive symptomatic patients (181 men and 88 women) treated from January 2004 to August 2008 in the Department of Vascular, General and Oncologic Surgery was analyzed.

Results. Perioperative stroke-death rate (within 30 days after the surgery) in women was $6.8 \%$ (6/88) and $3.3 \%(6 / 181)$ in men ( $p>0.05)$. In the female group, none of the analyzed risk factors were associated with a higher risk of periprocedural incident, while in men, only hypercholesterolemia was a significant predictor of perioperative stroke (TC $>240$ vs 240 vs 200-240: $O R=6.59 ; 95 \%$ (l: $1.12-38.97 ; p=0.0375$ ).

Conclusions. In men, hypercholesterolemia significantly increased the risk of perioperative stroke or death, while in females, none of the analyzed factors were determined as the predictors of the incident. The fact that plaque type VI by AHA was significantly more frequent in women and men more frequently were suffering from ischemic heart disease and peripheral artery occlusive disease appeared not to influence the outcome of CEA.
\end{abstract}

Key words: carotid endarterectomy, perioperative stroke, gender

DOI

10.17219/acem/68270

Copyright

Copyright by Author(s)

This is an article distributed under the terms of the

Creative Commons Attribution Non-Commercial License

(http://creativecommons.org/licenses/by-nc-nd/4.0/) 


\section{Introduction}

Carotid endarterectomy (CEA) is a surgical procedure used in ischemic brain stroke prevention in patients with symptomatic and asymptomatic severe carotid artery stenosis. Symptomatic carotid artery stenosis is characterized by amaurosis fugax (AF), transient ischemic attack (TIA) or ischemic stroke. International trials like the North American Symptomatic Carotid Endarterectomy Trial (NASCET) and the European Carotid Surgery Trial (ECST) were independently conducted to assess the safety and efficacy of CEA, compared to the best medical therapy at that time, in patients with recently symptomatic stenosis. ${ }^{1,2}$ These trials have helped to define the current indications for CEA. The NASCET found that for every 6 patients treated, 1 major stroke would be prevented at 2 years (i.e., the number needed to treat (NNT) out of 6) for symptomatic patients with a 70-99\% stenosis. ${ }^{1}$ CEA should also be considered as a method of stroke prevention before routinely performed coronary artery bypass grafting $(\mathrm{CABG})$ in patients with hemodynamically significant carotid artery stenosis. Moreover, simultaneous CEA-CABG operations are effectively performed in patients at high risk of cardiac and neurologic complications. ${ }^{3}$

The guidelines for the management of extracranial artery stenosis are still being discussed in the literature. A post-hoc analysis of the NASCET and ECST showed groups of patients who benefitted the most from CEA. A secondary examination of these research papers facilitated the creation of a stroke-risk profile based on medical, neurological and angiographic findings. ${ }^{4-6}$ The data obtained from the research revealed that, in addition to the degree of stenosis, there were other important factors for the outcome of CEA such as age, gender, neurological symptoms, and others connected with subsequent stroke or surgical risk. It was found that plaque ulceration also increased the risk of stroke. For an ulcerated 95\% stenosis, the absolute risk reduction of ipsilateral stroke obtained by CEA was $54 \%{ }^{1,7}$ In the multicenter NASCET study, it was observed that women have a higher perioperative rate of stroke or death than men, however, these results were not statistically significant, while the ECST detected a significant increase in perioperative stroke and death in women compared with men. ${ }^{2,8}$ The poorer surgical outcomes of endarterectomy in women are contributed to several factors, like vessel diameter, sensitivity to antiplatelet therapy, sex hormones, plaque composition and morphology, emboli, and restenosis rate. ${ }^{9-11}$ The recently-published CREST (Carotid Revascularization Endarterectomy vs Stenting Trial) results showed that CEA is associ- ated with similar rates of periprocedural stroke in women and men. ${ }^{12}$ Some research has also confirmed that female sex is not independently associated with higher mortality or a higher stroke rate during CEA. ${ }^{13-15}$

In this paper, we critically analyzed the outcome of surgical treatment of patients with internal carotid artery stenosis in our department. The aim of this research is to compare perioperative stroke or death rate after CEA in male and female patients. Furthermore, it seeks to determine risk factors of perioperative stroke or death in women and men with internal carotid artery stenosis treated with CEA.

\section{Material and methods}

\section{Participants}

The outcome of surgical treatment of 269 consecutive symptomatic patients with internal carotid artery stenosis was analyzed. The patients were hospitalized from $1^{\text {st }}$

Table 1. Comparison of characteristics of the women's and men's groups

\begin{tabular}{|c|c|c|c|c|}
\hline Risk factor & $\begin{array}{l}\text { Women } \\
(n=88)\end{array}$ & $\begin{array}{c}\text { Men } \\
(n=181)\end{array}$ & $\begin{array}{c}\text { Total } \\
(n=269)\end{array}$ & $\begin{array}{c}\mathrm{X}^{2} \text { test } \\
\mathrm{p} \text {-value }\end{array}$ \\
\hline Ischemic heart disease & 17 & 57 & 74 & 0.0359 \\
\hline \multicolumn{4}{|l|}{ Blood pressure } & \multirow{3}{*}{0.7198} \\
\hline normal (<130/85) & 50 & 107 & 157 & \\
\hline high normal (130-139/85-89) & 38 & 74 & 112 & \\
\hline Arrhythmia & 8 & 32 & 40 & 0.0632 \\
\hline Peripheral artery occlusive disease & 13 & 67 & 80 & 0.0002 \\
\hline \multicolumn{4}{|l|}{ Body mass index $\left(\mathrm{kg} / \mathrm{m}^{2}\right)$} & \multirow{4}{*}{0.9372} \\
\hline normal weight (18.5-24.9) & 48 & 95 & 143 & \\
\hline overweight (25-29) & 33 & 72 & 105 & \\
\hline obesity (>30.0) & 7 & 14 & 21 & \\
\hline Cigarette use & 28 & 79 & 107 & 0.0629 \\
\hline \multicolumn{4}{|l|}{$\mathrm{TC}(\mathrm{mg} / \mathrm{dL})$} & \multirow{4}{*}{0.7184} \\
\hline$<200$ & 10 & 17 & 27 & \\
\hline $200-239$ & 60 & 132 & 192 & \\
\hline$>200$ & 18 & 32 & 50 & \\
\hline \multicolumn{4}{|l|}{$\mathrm{HDL}-\mathrm{C}(\mathrm{mg} / \mathrm{dL})$} & \multirow{3}{*}{0.5591} \\
\hline$>50$ for women and $>40$ for men & 27 & 62 & 89 & \\
\hline$<50$ for women and $<40$ for men & 61 & 119 & 180 & \\
\hline \multicolumn{4}{|l|}{$\mathrm{LDL}-\mathrm{C}(\mathrm{mg} / \mathrm{dL})$} & \multirow{4}{*}{0.8454} \\
\hline$<130$ & 16 & 30 & 46 & \\
\hline $130-159$ & 50 & 100 & 150 & \\
\hline$>130$ & 22 & 51 & 73 & \\
\hline \multicolumn{4}{|l|}{ Preoperative neurological symptom } & \multirow{4}{*}{0.4660} \\
\hline TIA & 7 & 23 & 30 & \\
\hline amaurosis fugax & 22 & 47 & 69 & \\
\hline stroke & 59 & 111 & 170 & \\
\hline Plaque type VI by AHA & 68 & 93 & 161 & $<0.0001$ \\
\hline
\end{tabular}

a - based on 3 separate blood pressure analyses. 
January, 2004 to $31^{\text {st }}$ August, 2008 in the Department of Vascular, General and Oncologic Surgery, Copernicus Memorial Hospital in Łódź. The examined group consisted of 181 (67.3\%) men (mean age $65 \pm 5$, min 44 years, $\max$ 76 years) and 88 (32.7\%) women (mean age $68 \pm 5$, min 42 years, max 79 years). All patients were symptomatic - they had had a cerebral stroke (confirmed by computer tomography), TIA or AF in the period from 4 weeks to maximum 6 months before the surgery. All the patients were treated with acetylsalicylic acid, statins, and anti-hypertension drugs. Demographic features (age, sex), concomitant diseases (ischemic heart disease, hypertension, arrhythmia, peripheral artery occlusive disease), BMI, cigarette smoking, and cholesterol level (TC, HDL, LDL) of the examined group were collected from medical documentation, which was prepared in accordance with the aim of this research.

\section{Procedure}

The patients had carotid artery Doppler ultrasonography performed, during which the degree of stenosis was assessed. All of them were classified to surgical treatment (CEA) - they had $70-84 \%$ or $85-99 \%$ stenoses according to NASCET criteria. ${ }^{16}$ Patients with bilateral high-grade stenoses had only the artery with a higher stenosis rating operated on during the 1 hospitalization. During the surgical procedure, an overall superficial assessment of the atherosclerotic plaque was performed by 1 person unaware of the aim of this research, a vascular surgeon specialist (M.亡). During the assessment procedure, all the plaques were cut open. On the basis of the AHA classification of plaques, the authors divided the examined plaques into 2 groups: type VI or other types by AHA. ${ }^{17,18}$ Type VI atherosclerotic plaque, according to AHA, is characterized by plaque rupture, intraplaque hemorrhage, thrombus on the plaque surface, large lipid core, and less fibrous tissue. ${ }^{18}$

Postoperatively, the patient was returned to the intensive care unit for a period of $24 \mathrm{~h}$. All of the patients since the $2^{\text {nd }}$ day after surgery continued their previous pharmacotherapy (statins, acetylsalicylic acid, anti-hypertensive drugs).

Within 30 days after the surgery, the patients were assessed for early general complications (stroke or death). The adverse outcomes were documented by formal neurological examination by a neurologist in our hospital. Moreover, female and male groups were compared in the aspects of type of atherosclerosis plaque (type VI or other types according to AHA) and concomitant diseases.
Table 2. Risk factors and plaque types in the group of women examined

\begin{tabular}{|c|c|c|c|c|}
\hline \multirow[b]{2}{*}{ Risk factor } & \multicolumn{3}{|c|}{ Perioperative stroke/death } & \multirow{2}{*}{$\begin{array}{c}\mathrm{X}^{2} \text { test } \\
\mathrm{p} \text {-value }\end{array}$} \\
\hline & $\begin{array}{c}\text { yes } \\
(n=6)\end{array}$ & $\begin{array}{c}\text { no } \\
(n=82)\end{array}$ & $\begin{array}{c}\text { total } \\
(\mathrm{n}=88)\end{array}$ & \\
\hline Age & $65 \pm 8$ & $68 \pm 5$ & $68 \pm 5$ & 0.4715 \\
\hline Ischemic heart disease & 2 & 15 & 17 & 0.3677 \\
\hline \multicolumn{4}{|l|}{ Blood pressure ${ }^{a}$} & \multirow{3}{*}{0.1744} \\
\hline normal $(<130 / 85)$ & 5 & 45 & 50 & \\
\hline high normal (130-139/85-89) & 1 & 37 & 38 & \\
\hline Arrhythmia & 1 & 7 & 8 & 0.5037 \\
\hline Peripheral artery occlusive disease & 2 & 11 & 13 & 0.1844 \\
\hline \multicolumn{4}{|l|}{ Body mass index $\left(\mathrm{kg} / \mathrm{m}^{2}\right)$} & \multirow{4}{*}{0.6993} \\
\hline normal weight (18.5-24.9) & 4 & 44 & 48 & \\
\hline overweight (25-29) & 2 & 31 & 33 & \\
\hline obesity (>30.0) & 0 & 7 & 7 & \\
\hline Cigarette use & 3 & 25 & 28 & 0.3219 \\
\hline \multicolumn{4}{|l|}{$\mathrm{TC}(\mathrm{mg} / \mathrm{dL})$} & \multirow{4}{*}{0.5337} \\
\hline$<200$ & 0 & 10 & 10 & \\
\hline $200-239$ & 4 & 56 & 60 & \\
\hline$>200$ & 2 & 16 & 18 & \\
\hline \multicolumn{4}{|l|}{$\mathrm{HDL}-\mathrm{C}(\mathrm{mg} / \mathrm{dL})$} & \multirow{3}{*}{0.2878} \\
\hline$>50$ for women and $>40$ for men & 3 & 24 & 27 & \\
\hline$<50$ for women and $<40$ for men & 3 & 58 & 61 & \\
\hline \multicolumn{4}{|l|}{$\mathrm{LDL}-\mathrm{C}(\mathrm{mg} / \mathrm{dL})$} & \multirow{4}{*}{0.8871} \\
\hline$<130$ & 1 & 15 & 16 & \\
\hline $130-159$ & 3 & 47 & 50 & \\
\hline$>130$ & 2 & 20 & 22 & \\
\hline \multicolumn{4}{|l|}{ Preoperative neurological symptom } & \multirow{4}{*}{0.2055} \\
\hline $\mathrm{TIA}$ & 0 & 7 & 7 & \\
\hline amaurosis fugax & 0 & 22 & 22 & \\
\hline stroke & 6 & 53 & 59 & \\
\hline Plaque type VI by AHA & 6 & 62 & 68 & \\
\hline
\end{tabular}

- based on 3 separate blood pressure analyses.

\section{Statistical analysis}

Women and men were compared across their characteristics using $X^{2}$ test. The statistical comparison included perioperative stroke or death in relation to concomitant diseases and plaque morphology in women and men. As a measure of this correlation, $\chi^{2}$ test and logistic regression analysis were applied. Uni- and multivariate logistic regression were performed to determine the factors or combination of factors accounting for the occurrence of periprocedural stroke in all patients and in female and male groups separately. P-value $\mathrm{p}<0.05$ was accepted as the level of significance. Statistical analysis was conducted using the STATA 9 statistical package (StataCorp LLC, College Station, USA). 
Table 3. Risk factors and plaque types in the group of men examined

\begin{tabular}{|c|c|c|c|c|}
\hline \multirow[b]{2}{*}{ Risk factor } & \multicolumn{3}{|c|}{ Perioperative stroke/death } & \multirow{2}{*}{$\begin{array}{c}\mathrm{x}^{2} \text { test } \\
\mathrm{p} \text {-value }\end{array}$} \\
\hline & $\begin{array}{c}\text { yes } \\
(n=6)\end{array}$ & $\begin{array}{c}\text { no } \\
(n=175)\end{array}$ & $\begin{array}{c}\text { total } \\
(n=181)\end{array}$ & \\
\hline Age & $63 \pm 6$ & $65 \pm 5$ & $65 \pm 5$ & 0.0820 \\
\hline Ischemic heart disease & 6 & 51 & 57 & 0.0002 \\
\hline \multicolumn{4}{|l|}{ Blood pressure } & \multirow{3}{*}{0.2198} \\
\hline normal (<130/85) & 5 & 102 & 107 & \\
\hline high normal (130-139/85-89) & 1 & 73 & 74 & \\
\hline Arrhythmia & 3 & 29 & 32 & 0.0348 \\
\hline Peripheral artery occlusive disease & 2 & 65 & 67 & 0.8493 \\
\hline \multicolumn{4}{|l|}{ Body mass index $\left(\mathrm{kg} / \mathrm{m}^{2}\right)$} & \multirow{4}{*}{0.0603} \\
\hline normal weight (18.5-24.9) & 6 & 89 & 95 & \\
\hline overweight (25-29) & 0 & 72 & 72 & \\
\hline obesity (>30.0) & 0 & 14 & 14 & \\
\hline Cigarette use & 4 & 75 & 79 & 0.2476 \\
\hline \multicolumn{4}{|l|}{$\mathrm{TC}(\mathrm{mg} / \mathrm{dL})$} & \multirow{4}{*}{0.0689} \\
\hline$<200$ & 1 & 16 & 17 & \\
\hline $200-239$ & 2 & 130 & 132 & \\
\hline$>200$ & 3 & 29 & 32 & \\
\hline \multicolumn{4}{|l|}{$\mathrm{HDL}-\mathrm{C}(\mathrm{mg} / \mathrm{dL})$} & \multirow{3}{*}{0.9614} \\
\hline$>50$ for women and $>40$ for men & 2 & 60 & 62 & \\
\hline$<50$ for women and $<40$ for men & 4 & 115 & 119 & \\
\hline \multicolumn{4}{|l|}{$\mathrm{LDL}-\mathrm{C}(\mathrm{mg} / \mathrm{dL})$} & \multirow{4}{*}{0.5397} \\
\hline$<130$ & 0 & 30 & 30 & \\
\hline $130-159$ & 4 & 96 & 100 & \\
\hline$>130$ & 2 & 49 & 51 & \\
\hline \multicolumn{4}{|l|}{ Preoperative neurological symptom } & \multirow{4}{*}{0.2231} \\
\hline TIA & 2 & 21 & 23 & \\
\hline amaurosis fugax & 2 & 45 & 47 & \\
\hline stroke & 2 & 109 & 111 & \\
\hline Plaque type VI by AHA & 5 & 88 & 93 & 0.1113 \\
\hline
\end{tabular}

a - based on 3 separate blood pressure analyses.

Table 4. Uni- and multivariate logistic regression analysis of risk factors in men

\begin{tabular}{|c|c|c|c|}
\hline \multirow{2}{*}{ Risk factor } & \multicolumn{3}{|c|}{ Univariate analysis } \\
\hline & OR & $95 \% \mathrm{Cl}$ & $p$-value \\
\hline Age & 0.88 & $(0.74 ; 1.05)$ & 0.1548 \\
\hline \multirow{2}{*}{$\begin{array}{l}\text { Arrhythmia } \\
\text { yes vs no }\end{array}$} & & & \multirow{2}{*}{0.0547} \\
\hline & 5.03 & $(0.97 ; 26.19)$ & \\
\hline \multicolumn{3}{|l|}{$\mathrm{TC}$} & \multirow{3}{*}{0.0375} \\
\hline$>240$ vs $<200$ & 2.57 & $(1.06 ; 6.24)$ & \\
\hline$>240$ vs $200-240$ & 6.59 & $(1.12 ; 38.97)$ & \\
\hline Risk factor & \multicolumn{3}{|c|}{ Multivariate analysis } \\
\hline \multicolumn{3}{|l|}{$\mathrm{TC}$} & \multirow{3}{*}{0.0375} \\
\hline$>240$ vs $<200$ & 2.57 & $(1.06 ; 6.24)$ & \\
\hline$>240$ vs $200-240$ & 6.59 & $(1.12 ; 38.97)$ & \\
\hline
\end{tabular}

Univariate analysis for IHD and BMI was not performed because some categorical variables equal zero.

\section{Results}

The characteristics of the groups of women and men are presented in Table 1. Men significantly more frequently than women suffered from ischemic heart disease $(\mathrm{p}=0.0359)$ and peripheral artery occlusive disease $(\mathrm{p}=0.0002)$ while in women, AHA plaque type VI occurred significantly more often than in men $(\mathrm{p}<0.0001)$ (Table 1).

In all of the patients, the perioperative strokedeath rate after CEA was 4.5\% (12/269) - 6.8\% $(6 / 88)$ in the female group and $3.3 \%(6 / 181)$ in men ( $\mathrm{p}>0.05)$.

In the female group, none of the analyzed risk factors were associated with a higher risk of periprocedural stroke or death, and none could be included in uni- or multivariate regression ( $p>0.1$ for all items) (Table 2).

In men, statistical analysis showed that perioperative stroke or death was significantly more frequent in those with ischemic heart disease and arrhythmia $(p<0.05)$. Variables with $\mathrm{p}<0.1$ were included in the univariate logistic regression analysis (age, ischemic heart disease, arrhythmia, BMI, TC). Uni- and multivariate logistic regression analysis showed that from all of the analyzed risk factors, only hypercholesterolemia was a significant predictor of periprocedural stroke (TC $>240 \mathrm{vs}<200$ : OR $=2.57 ; 95 \%$ CI: $1.06-6.24 ;>240$ vs $200-$ 240: $\mathrm{OR}=6.59 ; 95 \%$ CI: $1.12-38.97 ; \mathrm{p}=0.0375$ ) (Tables 3, 4).

Additionally, the characteristics of all patients, regardless of their sex, were included in logistic regression analysis, which showed that ischemic heart disease and AHA plaque type VI were risk factors of perioperative stroke or death (IHD: $\mathrm{OR}=6.1 ; 95 \% \mathrm{CI}: 1.75-21.26 ; \mathrm{p}=0.0045$; plaque type: $\mathrm{OR}=8.37 ; 95 \%$ CI: $1.05-66.75 ; \mathrm{p}=0.045)($ Table 5).

\section{Discussion}

We examined the outcomes of CEA in the aspect of potential risk factors for perioperative stroke or death in a male and female group of 269 patients. We found that plaque type VI according to AHA was significantly more common in women, however none of the analyzed factors were associated with a higher risk of periprocedural stroke or death in this group. The risk of periprocedural incident was influenced in a statistically significant fashion by hypercholesterolemia in men.

Several studies have confirmed a difference in outcome after carotid surgical treatment of carotid arteries stenoses between men and women. Hayes et al. observed that 
women developed more than a 2 -fold increase in the number of emboli in the postoperative period. The authors found that a possible explanation for the increased rate of complications after CEA was the increased thromboembolic potential of women. ${ }^{19}$ Laman et al. and Stork et al. described a higher level of microembolic signals in women in the postoperative period, which were associated with earlier cerebrovascular complications. ${ }^{20,21}$ On the basis of a literature review concerning the etiological factors responsible for different outcomes between women and men after CEA, several ones were distinguished: vessel diameter, plaque morphology, sex hormones, microembolic potential and restenosis. It is worth mentioning that none of the above-mentioned studies analyze more than 1 factor simultaneously. ${ }^{19-29}$

However, the overall evidence for outcome differences by gender-specific characteristics in the literature is limited. ${ }^{30}$ Mantese et al. found that sex did not modify the treatment effect. ${ }^{31}$ Some authors emphasize that female sex alone is not an adjunctive risk factor for poor outcome after CEA in comparison to male patients, however subgroups of female patients at ahigher surgical risk can be distinguished - with contralateral occlusion or diabetes. ${ }^{32}$

The idea that certain medical and angiographic characteristics have potential value in determining the perioperative risk in CEA has been discussed. ${ }^{5-7}$ The risk factor profiles obtained from the NASCET database included the presence of a hemispheric vs retinal TIA, leftsided procedure, contralateral carotid occlusion, ipsilateral ischemic lesion on CT scans, irregular or ulcerated

Table 5. Uni- and multivariate logistic regression analysis of risk factors in total group

\begin{tabular}{|c|c|c|c|}
\hline \multirow{2}{*}{ Risk factor } & \multicolumn{3}{|c|}{ Univariate analysis } \\
\hline & OR & $95 \% \mathrm{Cl}$ & $p$-value \\
\hline \multicolumn{3}{|l|}{ IHD } & \multirow{2}{*}{0.0052} \\
\hline yes vs no & 5.79 & $(1.69 ; 19.85)$ & \\
\hline \multicolumn{3}{|l|}{ Blood pressure } & \multirow{2}{*}{0.0927} \\
\hline high normal vs normal & 3.74 & $(0.8 ; 17.42)$ & \\
\hline \multicolumn{3}{|l|}{ Arrhythmia } & \multirow{2}{*}{0.0789} \\
\hline yes vs no & 3.07 & $(0.88 ; 10.72)$ & \\
\hline \multicolumn{3}{|l|}{ BMI } & \multirow{3}{*}{0.0512} \\
\hline $18.5-24.9$ vs $25-29$ & 4.29 & $(0.99 ; 18.5)$ & \\
\hline $18.5-24.9$ vs $>30$ & 18.36 & $(0.99 ; 342.25)$ & \\
\hline \multicolumn{3}{|l|}{ Plaque type by $\mathrm{AHA}$} & \multirow{2}{*}{0.0502} \\
\hline type VI vs other types & 7.85 & $(0.99 ; 61.70)$ & \\
\hline Risk factor & \multicolumn{3}{|c|}{ Multivariate analysis } \\
\hline \multicolumn{3}{|l|}{$\mathrm{IHD}$} & \multirow{2}{*}{0.0045} \\
\hline yes vs no & 6.1 & $(1.75 ; 21.26)$ & \\
\hline \multicolumn{3}{|l|}{ Plaque type by AHA } & \multirow{2}{*}{0.0450} \\
\hline type VI vs other types & 8.37 & $(1.05 ; 66.75)$ & \\
\hline
\end{tabular}

plaque on angiograms and timing of the surgery relative to the time of the qualifying ischemic event. None of the risk factors like diabetes mellitus, hypertension, hyperlipidemia, coronary artery disease, intermittent claudication or smoking significantly increased the perioperative risk, nor the age or sex of the patient. ${ }^{33}$ Type of anesthesia (general vs local) also does not affect perioperative mortality and morbidity in patients undergoing CEA. ${ }^{34}$ On the basis of the ECST results, 4 statistically significant risk factors were determined: ocular vs cerebral presenting symptoms; systolic hypertension $\geq 180 \mathrm{~mm} \mathrm{Hg}$; peripheral vascular disease; and female sex. ${ }^{35}$ It was also shown that in patients with intracranial occlusions and stenoses, perioperative and late strokes or vascular deaths appear more frequently in comparison to those without intracranial lesions. ${ }^{36}$ In contrast, some authors emphasize that contralateral stenosis $\geq 50 \%$ and previous symptoms of cerebral vascular accidents or intraoperative shunt insertion and postoperative high blood pressure may not be risk factors for increased complications after CEA. ${ }^{37}$

Our study revealed that female sex is connected with AHA plaque type VI presence (in gross eye view assessment in women undergoing CEA). Moreover, we found that the risk factors for perioperative stroke or death after CEA differ between women and men. Sex differences have been recognized in atherosclerotic plaque formation, cerebral stroke risk and occurrence of cardiovascular events. ${ }^{23}$ Some studies in relation to the hormone level in women and the occurrence of cardiovascular events proved that estrogens have a protective effect on atherogenesis, and, as a consequence, on clinical manifestations of atherogenesis. ${ }^{38}$ A literature review leads to the conclusion that carotid plaque type VI according to AHA occurs more often in symptomatic women with ICA stenosis than in men. However, carotid artery plaques obtained from asymptomatic women are more stable and less inflammatory compared to men. ${ }^{23}$ Irregular, ulcerated atherosclerotic plaques have important clinical significance. Such lesions have a tendency for disruptions that are often a source of distal emboli as well as occlusion, resulting in transient cerebral symptoms. Plaque type VI, in which disruptions of the lesion surface, hematoma or hemorrhage, and thrombotic deposits have developed, are largely responsible for morbidity and mortality from atherosclerosis. ${ }^{39}$ More studies focusing on specific factors affecting different outcomes between men and women after CEA simultaneously assessed in both symptomatic and asymptomatic patients are needed to draw clinically relevant conclusions.

In conclusion, the results of our research demonstrate that periprocedural complications after CEA did not differ between women and men. The fact that AHA plaque type VI was more frequent in women and men more frequently were suffering from ischemic heart disease and peripheral artery occlusive disease, appeared not to influence significantly the outcome of CEA. However, multivariate analysis 
including all patients, regardless of their sex, showed that those with ischemic heart disease and AHA type VI carotid atherosclerotic plaque are at a higher risk for periprocedural stroke. In men, contrary to women, hypercholesterolemia significantly increases the risk of the incident. Therefore, we believe that many different factors, not only the degree of stenosis, radiological characteristics, like regularity of atherosclerotic plaque and presence of intracranial disease, but also sex of the patient, should be taken into consideration when balancing the benefits and harms of ICA revascularization. In addition, further work is needed to develop the risk assessment tools specific to patients undergoing CEA.

\section{References:}

1. North American Symptomatic Carotid Endarterectomy Trial Collaborators. Beneficial effect of carotid endarterectomy in symptomatic patients with high grade stenosis. N Eng/ J Med. 1991;325:445-453.

2. European Carotid Surgery Trialists' Collaborative Group. Randomized trial of endarterectomy for recently symptomatic carotid stenosis: Final results for the MRC European Carotid Surgery Trial (ECST). Lancet. 1998;351:1379-1387.

3. Janczak D, Król P, Skiba J, Mak M. Jednoczasowe zabiegi udrożnienia tętnicy szyjnej wewnętrznej i pomostowania aortalno-wieńcowego. Doświadczenia własne. Kardiochir Torakochir Pol. 2012;1:33-37.

4. Rothwell P, Eliasziw M, Gutnickov S, et al. Analysis of pooled data from the randomised controlled trials of endarterectomy for symptomatic carotid stenosis. Lancet. 2003;361:107-116.

5. Naylor A, Rothwell P, Bell P. Overview of the principal results and secondary analyses from the European and North American randomized trials of endarterectomy for symptomatic carotid stenosis. Eur J Vac Endovasc Surg. 2003;26:115-129.

6. Rothwell P, Eliasziw M, Gutnikow S, Warlow C, Barnett H. Endarterectomy for symptomatic carotid stenosis in relation to clinical subgroups and timing of surgery. Lancet. 2004;363:915-924.

7. Mckinley S, White R, Dietrich E, et al. Carotid revascularisation using endarterectomy or stenting systems (CARESS): Phase 1 clinical trial. J Endovasc Ther. 2003;10:1021-1030.

8. Alamowitch S, Eliasziw M, Barnett HJM. The risk and benefit of endarterectomy in women with symptomatic internal carotid artery disease. Stroke. 2005;36:27-31.

9. Harthun NL, Kongable GL, Baglioni AJ, Meakem TD, Kron IL. Examination of sex as an independent risk factor for adverse events after carotid endarterectomy. J Vasc Surg. 2005;41:223-230.

10. Harthun NL, Cheanvechai V, Graham LM, Freischlag JA, Gahtan V. Outcome of carotid endarterectomy on the basis of patient sex: Is there a difference? J Thorac Cardiovasc Surg. 2004;127:322-324.

11. Hulley S, Grady D, Bush T, et al. Randomized trial of estrogen plus progestin for secondary prevention of coronary heart disease in postmenopausal women. Heart and Estrogen/progestin Replacement Study (HERS) Research Group. JAMA. 1998;280:605613.

12. Howard VJ, Lutsep HL, Mackey A, et al. Influence of sex on outcomes of stenting versus endarterectomy: A subgroup analysis of the Carotid Revascularization Endarterectomy versus Stenting Trial (CREST). Lancet Neurol. 2011;10:530-537.

13. Akbari CM, Pulling MC, Pomposelli FB, Gibbons GW, Campbell DR, LoGerfo FW. Gender and carotid endarterectomy: Does it matter? J Vasc Surg. 2000;31:1103-1109.

14. Schneider JR, Droste JS, Golan JF. Carotid endarterectomy in women versus men: Patient characteristics and outcomes. J Vasc Surg. 1997;25:890-898.

15. James DC, Hughes JD, Mills JL, Westbrand A. The influence of gender on complications of carotid endarterectomy. Am J Surg. 2001;182:654-657.

16. Kappelle LJ, Eliasziw M, Fox AJ, Sharpe BL, Barnett HJM. Importance of intracranial atherosclerotic disease in patients with symptomatic stenosis of the internal carotid artery. Stroke. 1999;30:282-286.
17. Timler D, Stelagowski M, Kasielska A, Bogusiak K, Tazbir J. Analysis of surgical treatment of patients with carotid artery stenosis endarterectomy versus stenting. Acta Chir Belg. 2007;107:146-150.

18. Stary HC, Chandler AB, Dinsmore RE, et al. A definition of advanced types of atherosclerotic lesions and a histological classification of atherosclerosis: A report from the committee on vascular lesions of the Council on Arteriosclerosis, American Heart Association. Arterioscler Thromb Vasc Biol. 1995;15:1512-1531.

19. Hayes PD, Payne DA, Evans NJ, et al. The excess of strokes in female patients after CEA is due to their increased thromboembolic potential: Analysis of 775 cases. Eur J Vasc Endovasc Surg. 2003;26:665-669.

20. Laman DM, Wieneke GH, van Duijn $H$, van Huffelen AC. High embolic rate early after carotid endarterectomy is associated with early cerebrovascular complications, especially in women. $J$ Vasc Surg. 2002;36:278-284.

21. Stork JL, Levi CR, Chambers BR, Abbott AL, Donnan GA. Possible determinants of early microembolism after carotid endarterectomy. Stroke. 2002;33:2082-2085.

22. Golledge J, Cuming R, Ellis M, Davies AH, Greenhalgh RM. Duplex imaging findings predict stenosis after carotid endarterectomy. J Vasc Surg. 1997;26:43-48.

23. Hellings WE, Pasterkamp G, Verhoeven BA, et al. Gender-associated differences in plaque phenotype of patients undergoing carotid endarterectomy. J Vasc Surg. 2007;45:289-296.

24. Lane JS, Shekherdimian S, Moore WS. Does female gender or hormone replacement therapy affect early or late outcome after carotid endarterectomy? J Vasc Surg. 2003;37:568-574.

25. Ackerstaff RG, Moons KG, van de Vlasakker CJV, et al. Association of intraoperative transcranial doppler monitoring variables with stroke from carotid endarterectomy. Stroke. 2000;31:1817-1823.

26. Golledge J, Gibbs R, Irving C, et al. Determinants of carotid microembolization. J Vasc Surg. 2001;34:1060-1064.

27. Horn J, Naylor AR, Laman DM, et al. Identification of patients at risk for ischaemic cerebral complications after carotid endarterectomy with TCD monitoring. Eur J Vasc Endovasc Surg. 2005;30:270-274.

28. Verhoeven BA, Pasterkamp G, de Vries JP, et al. Closure of the arteriotomy after carotid endarterectomy: Patch type is related to intraoperative microemboli and restenosis rate. J Vasc Surg. 2005;42:1082-1088.

29. Anderson A, Padayachee TS, Sandison AJ, Modaresi KB, Taylor PR. The results of routine primary closure in carotid endarterectomy. Cardiovasc Surg. 1999;7:50-55.

30. den Hartog AG, Algra A, Moll FL, de Borst GJ. Mechanisms of gender-related outcome differences after carotid endarterectomy. J Vasc Surg. 2010;52:1062-1071.

31. Mantese VA, Timaran CH, Chiu D, Begg RJ, Brott TG. CREST Investigators. The Carotid Revascularization Endarterectomy versus Stenting Trial (CREST): Stenting versus carotid endarterectomy for carotid disease. Stroke. 2010;41(Suppl 10):31-34.

32. Dorigo W, Pulli R, Marek J, Troisi N. Carotid endarterectomy in female patients. J Vasc Surg. 2009;50:1301-1307.

33. Ferguson GG, Eliasziw M, Barr HW, et al. The North American Symptomatic Carotid Endarterectomy Trial: Surgical results in 1415 patients. Stroke. 1999;30:1751-1758.

34. Markovic D, Vlajkovic G, Sindjelic R, Markovic D, Ladjevic N, Kalezic N. Cervical plexus block versus general anesthesia in carotid surgery: Single center experience. Arch Med Sci. 2012;8:1035-1040.

35. Rothwell PM, Slattery J, Warlow CP. Clinical and angiographic predictors of stroke and death from carotid endarterectomy: Systematic review. BMJ. 1997;315:1571-1577.

36. Stelągowski M, Bogusiak K, Kasielska A, Łysakowski M, Kaźmierski P, Szostek M. Intracranial occlusions and internal carotid artery stenoses: Clinical implications. Ann Vasc Surg. 2010;24:786-793.

37. Estruch-Pérez MJ, Plaza-Martínez A, Hernández-Cádiz MJ, Soliveres-Ripoll J, Solaz-Roldán C, Morales-Suarez-Varela MM. Interaction of cerebrovascular disease and contralateral carotid occlusion in prediction of shunt insertion during carotid endarterectomy. Arch Med Sci. 2012;8:236-243.

38. Denti L. The hormone replacement therapy (HRT) of menopause: Focus on cardiovascular implications. Acta Biomed. 2010;81:73-76.

39. Constantinides P. Plaque hemorrhages, their genesis and their role in supra-plaque thrombosis and atherogenesis. In: Glagov S, Newman WP, Schaffer SA, eds. Pathobiology of the Human Atherosclerotic Plaque. New York, NY: Springer-Verlag; 1990:394-411. 